\title{
Unravelling Secondary Students' Challenges in Digital Literacy: a Gender Perspective
}

\author{
Esther Argelagós ${ }^{1}$, Manoli Pifarré ${ }^{2}$ \\ ${ }^{1}$ Department of Psychology, Universitat de Girona, Spain \\ ${ }^{2}$ Department of Pedagogy and Psychology, Universitat de Lleida, Spain \\ Correspondence: Esther Argelagós, Department of Psychology, Universitat de Girona, Spain.
}

\author{
Received: April 2, $2016 \quad$ Accepted: December 1, $2016 \quad$ Online Published: December 7, 2016 \\ doi:10.11114/jets.v5i1.1517～URL: http://dx.doi.org/10.11114/jets.v5i1.1517
}

\begin{abstract}
The use of the Internet to learn involves complex cognitive activities. Educational researchers claim more attention in studying the nature of students' challenges when using digital information for learning purposes. Our research investigated in depth the challenges that secondary students face when solving web information-problem tasks. We thoroughly analysed how forty secondary students (18 girls and 22 boys) solved a scholar task using web information. The students' actions on the computer screen were logged. Findings showed specific difficulties in solving digital tasks due to when (1) typing appropriate search terms, and when (2) selecting reliable and useful results from a "search engine results page", which hinders the correct finding and understanding of web information needed to solve the digital task. In addition, the participants had a lack of reflection regarding the different actions to solve the digital task. Furthermore, our findings revealed that gender was not associated with differences in digital attainment.
\end{abstract}

Keywords: Information-problem solving (IPS), secondary education, classrooms; web search, skills, performance, gender differences

\section{Introduction}

Students in Secondary Education use Internet for both leisure and school assignments. However, it is widely accepted that the complex cognitive activities involved in gathering and processing information from the Web are not instinctively acquired (Wood, 2009). Previous research has shown that students have difficulties in mastering these skills (Badia \& Becerril, 2015; Bannert \& Reimann, 2011; Walraven, Brand-Gruwel, \& Boshuizen, 2008; Wood, 2009) and it is claimed that more research in studying the nature of these challenges is needed. This new research should fuel on well-designed and well-embedded scaffolds given to students in order to promote better students' digital skills development which will allow them to reach a stronger educational attainment (e.g., Raes, Schellens, De Wever, \& Vanderhoven, 2012). Our study falls in this line of research and the main goals are (1) to give insight about the challenges that secondary students face when solving tasks using web information to learn curricular contents at school, and (2) to seize gender differences on digital skills and task performance. These results will shed some light on instructional design to promote effective students' digital skills development in classroom settings.

To accomplish these two goals, we have divided this section in three main parts. First, we discuss the concept of digital literacy as an information-problem solving process. Second, we analyse previous studies on the students' challenges in developing effective skills in solving information problems. Third, we review current literature about gender differences on the use of Internet in scholar learning. After the introduction section, we outline our research methodology. Finally, we analyse and discuss the results obtained in our study and its educational implications focusing on better-designed and better-embedded scaffolds.

\subsection{Digital Literacy as an Information-problem Solving Process}

Information-problem solving (IPS) has been defined as the process that involves complex cognitive activities to solve a problem using web information (Eisenberg \& Berkowitz, 1990; Brand-Gruwel, Wopereis, \& Vermetten, 2005; Brand-Gruwel, Wopereis, \& Walraven, 2009; Brand-Gruwel \& Stadler, 2011).

The IPS process can be segmented into several skills (Brand-Gruwel et al., 2005): (1) An information problem is defined. (2) A search engine (i.e., Google) is usually selected, where a query with search terms is entered. Consequently, a "search 
engine result page" (SERP) with a list of search result links is displayed to the user. (3) Those search results are assessed by checking the information that each result contains: i,e., title, summary, and "uniform resource locators" (URL). (4) After accessing a selected web page, its information is scanned, evaluated, and extracted for further processing in case of relevant information. (5) The information from different web pages is integrated in order to solve the problem. Each skill is decomposed into several skills. For instance, the skill "search for information" is constituted by the skills "specify search terms" and "judge results from a SERP", as was proposed by Brand-Gruwel et al. (2005) in their IPS model (Figure 1).

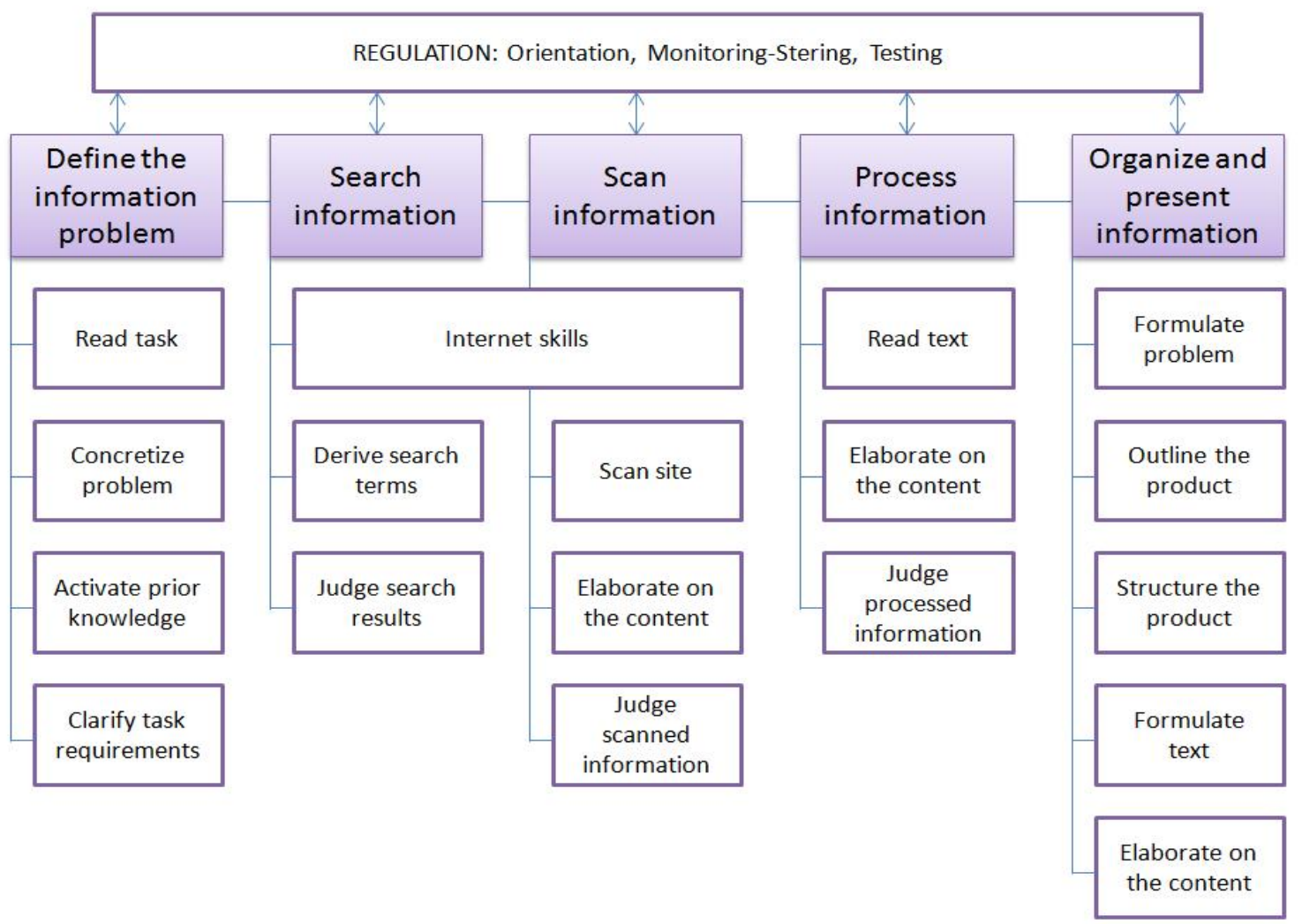

Figure 1. Information-problem solving (Brand-Gruwel et al., 2005; 2009)

Several studies have reported that users of all ages, and especially secondary students, struggle in the development of IPS skills. In the next section, we review those challenges, and for this revision we will follow the skill decomposition model proposed.

\subsection{Challenges Faced by Secondary Students in Information-problem Solving Tasks}

In this section, we review the challenges that secondary students usually face while solving information problems. We divide this revision in two main parts: challenges related to the IPS process (constituent skills and skills), and difficulties to attain a final product.

\subsubsection{Information-problem Solving Process}

In reference to the constituent skill 'Defining the problem', previous research shows that secondary students have difficulties in the next four sub skills: formulating questions (Wallace, Kupperman, Krajcik, \& Soloway, 2000), activating prior knowledge, clarifying task requirements, and determining needed information (Walraven et al., 2008). Besides, most students start searching with no much reflection about the topic and the task and without outlining the search (Fidel et al., 1999, Ladbrook \& Probert, 2011).

In relation to the constituent skill "Searching for information", secondary students have problems in selecting the appropiate "search terms" (Badilla-Quintana, Cortada-Pujol, Riera-Romaní, 2011; MaKinster, Beghetto, \& Plucker, 2002; Van Deursen, Görzig, Van Delzen, Perik, \& Stegeman 2014; Wallace et al., 2000). Most of the times, students do a general search when they navigate the hypermedia environment rather than having specific searching objectives (Azevedo, Cromley, \& Seibert, 2004). Furthermore, students do not systematically "judge the search results" and therefore they have difficulties to consult reliable web sources which have been chosen attending to superficial cues as the title or the web site briefing (Rouet, Ros, Goumi, Macedo-Rouet, \& Dinet, 2011). 
To "Scanning information", teenagers also have problems in choosing between reputable and questionable sources, and selecting and assessing web site information (Lorenzen, 2002; Ladbrook \& Probert, 2011; Van Deursen et al., 2014). As a result, the information selected may either come from a commercial or a scientific source (Fidel et al., 1999; Mason, Ariasi, \& Boldrin, 2011).

Concerning the constituent skill "Processing information", expert searchers spend more time on elaborating the content than novices (Brand-Gruwel et al., 2005). In the same line, Goldman (2011) found that the amount of time spent on a site was another key difference between novice and expert searchers. The former ones spent more time on reliable sites whereas the novice did not differentiate them.

Finally, to "Organizing and presenting information", students predominantly use ineffective strategies such as copying information from the hypermedia environment to their notes (Azevedo et al., 2004) and have the tendency to "copy and paste" the web information in order to solve the scholar tasks (Probert, 2009). In addition, Raes et al. (2012) also observed that students tend to reduce the whole task to find a straightforward answer on a particular web site instead of reading critically and thoroughly the web information.

To sum up, there are experimental evidences that support secondary-school students face serious challenges during the IPS process which hinders potential learning outcomes by using Internet in classroom activities. Therefore, instructional design is needed to help students developing effective skills and sub skills to solve IPS task.

\subsubsection{Task Performance}

The learning outcome obtained in an IPS task can be presented as a writing essay or as a set of answers to specific questions (Jonassen \& Kim, 2009), among others. In the literature, this type of learning outcome has also been named "task performance". An essay requires content understanding and developing arguments during IPS task that can be used as an assessment instrument to value educational attainment. Content understanding is not only a recollection of facts and definitions associated with a particular subject area, but it can be viewed as a matter of degree in which an individual understands concepts, principles, structures, or processes at a relatively deep level and it is able to show certain behaviour patterns (Nickerson, 1995). Therefore, understandings could be made evident to others in terms of overt behaviours as learners communicate or act in five ways (Häkkarainen, 2003): (1) Separated, Simple Low-Level Facts. (2) Partially-Organised Facts. (3) Well-Organised Facts. (4) Partial Explanation. (5) Explanation.

Furthermore, another approach to assess students' writing processes and learning attainment is the proposal made by made Scardamalia and Bereiter (1991), who made a distinction between knowledge telling and knowledge transforming. In a similar vein, Priemer and Ploog (2007), depending on the ways students used information obtained from the Web, they were classified into two types: compilers, who usually copied text from Web sources and lacked adequate processing of the information; and authors, who created an original and more elaborated text.

To sum up, a written response to an information problem is a complex activity because writing using information that comes from multiple documents entails complex cognitive processes (Raes et al., 2012; Wiley \& Voss, 1999), in which students of all ages face many difficulties that should be guided through a well-design educational intervention.

\subsection{Gender Differences}

Gender has been recognized as an important variable that influences skills related with computers (Chen \& Macredite, 2010; Young, 2000). Literature has suggested that females report higher levels of computer anxiety than their male counterparts; in addition, males achieve much better outcomes than females when using computers (Karavidas, Lim, \& Katsikas, 2005). Chen and Fu (2009) analysed a sample of 1,409 secondary-school students in Northern Taiwan and pointed out that the frequency of Internet used by girls was significantly lower than by boys, and that boys and girls differed in their patterns of Internet use. Similarly, Tsai and Tsai (2010) reported that male students were more active Internet users than their female counterparts; however, boys used the Web mainly for exploration and girls had the tendency of using it for communication issues, as also reported by Jackson, Von Eye, Witt, Zhao, and Fitzgerald (2011).

Large, Beheshti, and Rahman (2002), in a study with 11 year-old children, pointed out that boys were more actively engaged in navigating on Internet than girls. Particularly, boys submitted more search terms in search engines, explored the hyperlinks more frequently, visited more webpages per minute, gathered and saved information more often than girls. Consequently, the former visited less webpages as they spent more time viewing pages than boys (Arcand, Nantel, \& Sénécal, 2011) than their equals.

In this line of research, Zhou (2014) analysed 107 Chinese university students' perceptions about the use of Internet to learn and also found that males were more active in web searching than females, as they performed a larger number of searches and search queries.

These findings are similar to those of Roy and Chi (2003), who showed that boys tended to execute more page shifts per 
minute, by oscillating between entering searches and scanning the web pages excerpts returned (horizontal searchers), more than girls; conversely, girls had a tendency to actually open and browse entire linked document (vertical searchers). However, Lorigo, Pan, Hembrooke, Joachims, Granka, and Gay (2006) analysed gender differences through eye-tracking data and reported that boys' navigation patterns were more linear than girls', and these returned more often to previously visited abstracts when they searched web information.

Furthermore, Tsai (2009) examined male and female' search strategies in the behavioural, procedural and metacognitive domains through self-reported measures in a sample of 324 high school students. Gender difference was found in Internet control group. Therefore, although boys usually have higher self-assessed web skills, their current search skills may not be statistically different from girls (Hargittai \& Shafer, 2006).

Despite the differences between boys and girls patterns while working with digital information, these results are not conclusive as some other research studies did not show such differences. For example, in a study conducted with 340 Greek high-school students were not find gender differences in Internet searching skills (Papastergiou \& Solomonidou, 2005). Likewise, Van Deursen and Van Diepen (2013) in a study with Dutch adolescents on Internet skills did not reveal any gender differences. In addition, Walhout Brand-Gruwel, Jarodzka, van Dijk, de Groot, and Kirschner (2015) neither found differences in task performance between girls and boys when learning in hypertext environment in an eye-tracking study.

The above mentioned research on gender difference in navigation and Internet skills, not only has showed controversial results, but it has neither analysed the potential relation between web-search skills and task results. Consequently, our research pretends to fill this research gap by analysing the impact of the IPS skills used in task performance and gender variability.

\subsection{Research Objectives}

The objectives of this study are the following three:

(1) To analyse in detail the challenges that secondary students face while solving an information problem, regarding the IPS process - constituent skills and sub skills - and task performance.

(2) To examine gender differences in IPS process and task performance.

(3) To draw educational implications in better-designed instructions able to develop students' efficient IPS by taking advantage of the Web potential as a resource for learning

\section{Method}

\subsection{Participants}

Forty students (18 girls and 22 boys) participated in this study. All of them were middle secondary aged 13/14 year-old. The students belonged to three urban schools in the city of Lleida (Spain) and they have not previously received any specific instruction in IPS skills and neither participated in any teaching innovation project involving the use of Information and Communication Technologies.

\subsection{Design and Procedure}

Students were evaluated by solving an IPS task. This task was designed by the teachers and the research group in order to assess students' IPS process and task performance. The task was solved individually, in the students' regular classroom and it lasted about 45 minutes.

The IPS task was divided into two main parts. Part 1 was a fact-finding task in which participants were asked to complete a concept map and collect information about planet Mars (physical characteristics, orography, atmosphere, climate, satellites). Part 2 was carried out through an information-gathering task, in which participants had to accomplish three steps: (2.1) explaining the conditions a planet must have to make life possible by using information from the Web, (2.2) describing the favourable and unfavourable conditions of Mars, and (2.3) writing an argumentative essay about the possibility of installing a human colony on Mars and if so, what difficulties would have to be overcome and why.

\subsection{Data Instrument}

Students' actions to solve the IPS task were logged in the real context of the classroom by using a screen capture software called CamStudio 2.0.

\subsection{Data Analysis and Procedure}

Regarding the analysis of the IPS process, we considered two types of information retrieved from the log files: constituent skills and sub skills. In reference to the task performance, we assessed the answers given to the different questions of the task, and the final essay written by the participants. Table 1 shows a summary of the variables analysed and their 
measurement, and Figure 2 gives an overview of the inter relation between the variables and its iterative performance (Eisenberg \& Berkowitz, 1990).

Table 1. Variables analysed and their measurement

\begin{tabular}{ll}
\hline Variables & Measurement \\
\hline Process & Time spent and frequencies \\
Constituent skills & \\
1. Defining the problem & \\
2. Searching for information & \\
3. Scanning and processing information & \\
4. Organizing and presenting information & \\
Sub skills & Appropriateness score \\
5. Search terms & \\
6. Selected results & \\
Task performance & \\
7. Answers & Correctness score \\
8. Information-gathering answers & Elaboration level \\
9. Final essay & Explanation level \\
\hline
\end{tabular}

PROCESS

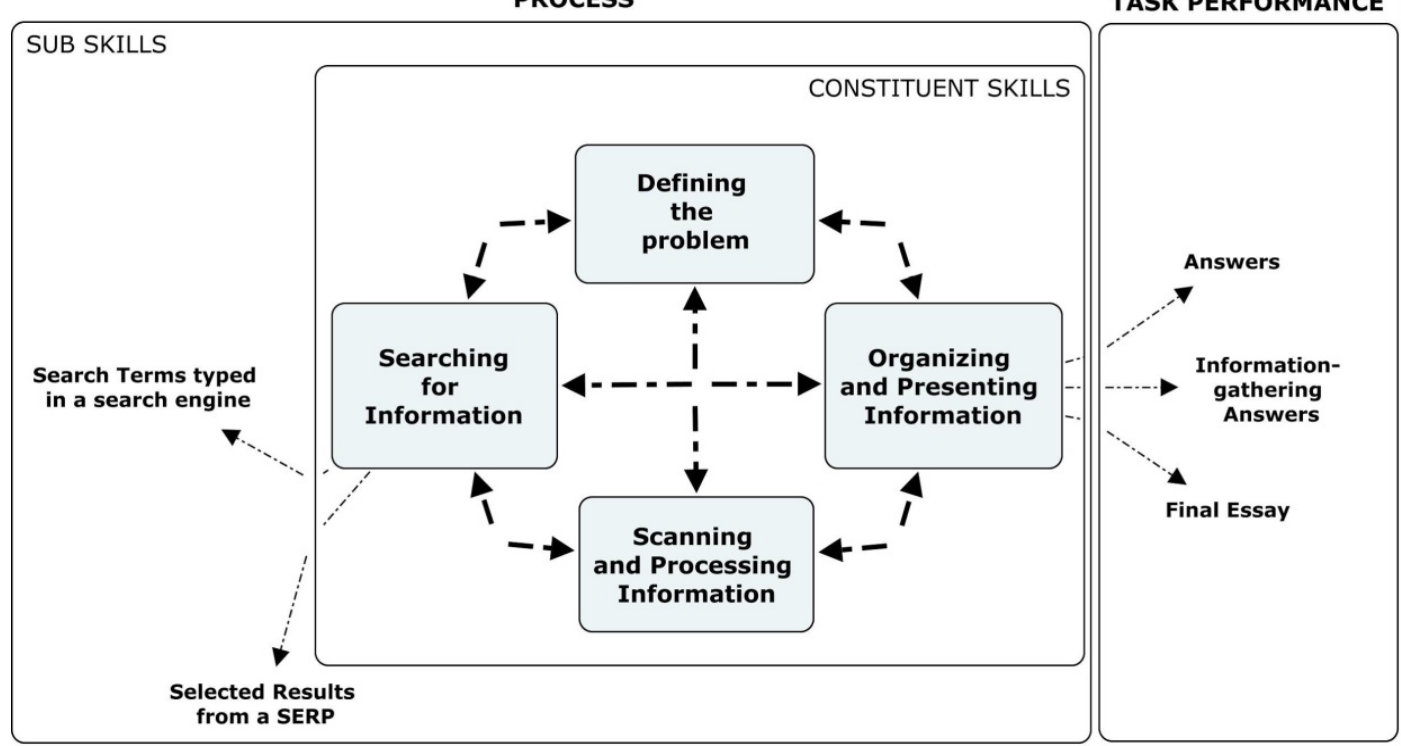

Figure 2. Information-problem solving model (Brand-Gruwel et al., 2005; 2009)

One log file per student was obtained. Each log file was transcribed in detail and, as a result, a protocol was obtained from each log file. Each protocol consisted of three main parts. The first part was devoted to the constituent skills and contained the following columns: time line, constituent skill performed, and duration of the skill performed. The second part was devoted to the web search sub skills and consisted in the following columns: search terms typed, correct search terms, appropriateness of the search terms, selected results, correct selected results, and appropriateness of the selected results. The third part of each protocol was about the task performance and contained the following columns: students' answers, answers correctness, elaboration level, and explanation level.

\subsubsection{Data Analyses of the Process Variables}

The first set of variables analysed referred to the constituent skills: (1) Defining the problem, (2) Searching for information, (3) Scanning and processing information, and (4) Organizing and presenting the information (Brand Gruwel et al., 2005; 2009). Each constituent skill was coded, including the time spent and the frequency. Short descriptions of these constituent skills are provided in Table 2. 
Table 2. Coding scheme of constituent skills

\begin{tabular}{ll}
\hline Constituent skills & Short descriptions \\
\hline Defining the problem & $\begin{array}{c}\text { The student analyses the demand in the IPS task (the computer screen shows } \\
\text { the web page of the assignment demand), without typing anything. } \\
\text { The student searches for the information on the Web: accessing a search engine, } \\
\text { typing search terms on it, or selecting results from a SERP (the computer } \\
\text { screen shows the search engine or the SERP). }\end{array}$ \\
$\begin{array}{l}\text { Scanning and processing for information } \\
\text { information }\end{array}$ & $\begin{array}{l}\text { The student scans or processes the information on a web site. } \\
\text { Organizing and presenting } \\
\text { information }\end{array}$
\end{tabular}

The second set of variables analysed referred to the following sub skills: search terms typed and selected results. Two reasons drove us to only consider these sub skills: first, several studies have reported on the relationship between the search terms appropriateness and the selected results' evaluation with expertise in web searching (i.e., Lazonder, 2000), and also with the quality of the product (Willey, Goldman, Graesser, Sanchez, Ash, \& Hemmerich, 2009) and second, the kind of data obtained (log files) allows observing specific actions made by the subject with the mouse or keyboard (for example: search terms typed, results selected by clicking on them, etc.).

(1) Search Terms. Each search term typed was transcribed verbatim and the appropriateness of each search term was coded as "appropriate" (1 point) or "inappropriate" (0 points). For example, the search term "diameter of Mars" typed in Google when the participant was searching to answer what is Mars' diameter, was considered "appropriate", whereas "conditions of Mars for life" when the question was related to the conditions that make a planet suitable for life was coded as "inappropriate" because that search term referred only to Mars while the question's aim made reference to any planet. In addition, an appropriateness score was calculated as a percentage, considering the number of search terms used and the number of appropriate search terms.

(2) Selected Results. Each result that was selected from a SERP was gathered and also was coded as "appropriate" or "inappropriate". The criteria taken into account to evaluate each search result were both usability and reliability (Authors, 2012; Gerjets, Kammerer, \& Werner, 2011). A selected result was considered "usable" when its content (title, description, URL, and other information available in the SERP) followed the question to be answered, and was considered as "reliable" when the author or source was plausible. Each selected result was coded as "appropriate" (1 point) when it was both usable and reliable, and as "inappropriate" ( 0 points) when it was either not usable or unreliable. Again, an appropriateness score was calculated as a percentage considering the number of total selected results and the number of appropriate ones.

Two raters who were familiar with the search task, the materials and the coding scheme scored $20 \%$ of the protocols. Interrater reliability computed on this sub sample of protocols yielded a Cohen's kappa higher than .80. Finally, only one rater scored the remaining protocols.

\subsubsection{Data Analyses of the Task-performance Variables}

All the answers given and the final essay written by each participant were collected and evaluated. The evaluation of these answers was carried out in three different forms: (a) answer correctness, (b) elaboration level of the information-gathering answers, and (c) explanation level of the final essay.

(a) Answer correctness. Each student' answer was coded in a binary fashion as either "correct" ( 1 point) or "incorrect" ( 0 points). A correctness score was calculated by considering the percentage between the number of correct answers given and the maximum number of points to be obtained (16 points).

(b) Elaboration level. 7 questions out of the 16 required an elaborated answer from the students. We wanted to characterize the different forms students used web information to respond these questions by coding students' answers in eight grading categories, as summarized in Table 3. 
Table 3. Coding scheme of elaboration level on the information-gathering answers

\begin{tabular}{|c|c|c|}
\hline $\begin{array}{c}\text { Level of } \\
\text { elaboration }\end{array}$ & Category & $\begin{array}{l}\text { Short description: } \\
\text { The student... }\end{array}$ \\
\hline 1 & No answer & ...did not answer the question. \\
\hline 2 & Improperly Copy \& Paste & ...copied and pasted improper information to the question. \\
\hline 3 & Incorrect or incomplete & ...gave an incorrect or incomplete answer to the question. \\
\hline 4 & $\begin{array}{l}\text { Copy \& Paste with } \\
\text { Irrelevant Information }\end{array}$ & $\begin{array}{l}\text {...copied and pasted a correct answer, but (s)he added } \\
\text { irrelevant information that the question did not require. }\end{array}$ \\
\hline 5 & Copy \& Paste & ...copied and pasted a correct answer. \\
\hline 6 & Elaboration on the content & $\begin{array}{l}\text {...answered the question by including one or more of the } \\
\text { following elements: translation from another language, } \\
\text { insertion of own words, enumeration of concepts. }\end{array}$ \\
\hline 7 & $\begin{array}{l}\text { Integration of the } \\
\text { Information }\end{array}$ & $\begin{array}{l}\text {...answered the question by explaining with own words, } \\
\text { comparing or linking concepts. }\end{array}$ \\
\hline 8 & $\begin{array}{l}\text { Integration of the } \\
\text { Information and } \\
\text { Argumentation }\end{array}$ & $\begin{array}{l}\text {...answered the question by using some of the following } \\
\text { elements: own argumentation, own comments, giving } \\
\text { examples, presence of connectors (because, although, it } \\
\text { means, in such a way,...). }\end{array}$ \\
\hline
\end{tabular}

(c) Final essay explanation level. This variable informs about the level of content understanding and reasoning present in students' final essay. Each content idea of the final essay was classified using a four-step scale: (1) separate pieces of facts, (2) organized facts, (3) partial explanation, and (4) explanation. This scale was based on the scales proposed by Häkkarainen (2003).

Each participant essay was reviewed by two raters. In those scores where differences were found, the final score was decided after a consensus.

SPSS version 19.0 software was used for the data analysis, t-student was calculated, with confident intervals between $95 \%$ and $99 \%$, in order to identify differences considering the gender variable.

\section{Results and Discussion}

In this section, first we present and discuss the in-depth analysis of the challenges that secondary students face while solving an information-problem task, regarding the IPS process -constituent skills and sub skills- and task performance. Second, we study gender differences in the dependent variables of our study.

\subsection{In-depth Analysis of the Students' IPS Challenges (Research Objective 1)}

Table 4. Constituent skills, sub skills and correctness of the task performance

\begin{tabular}{lrr}
\hline Variables & $\mathrm{M}$ & $\mathrm{SD}$ \\
\hline Constituent skills & & \\
Time spent (in minutes) & & \\
1. Defining the problem & 8.46 & 2.53 \\
2. Searching for information & 14.23 & 3.59 \\
3. Scanning and processing information & 8.54 & 4.20 \\
4. Organizing and presenting information & 40.34 & 5.18 \\
Total & & 7.15 \\
Frequencies & 31.8 & \\
1. Defining the problem & 22.5 & 9.4 \\
2. Searching for information & 41.4 & 10.6 \\
3. Scanning and processing information & 16.5 & 16.1 \\
4. Organizing and presenting information & 112.2 & 9.0 \\
Total & & 35.8 \\
Sub skills & 53.68 & \\
5. Search terms: Appropriateness score & 66.33 & 21.62 \\
6. Selected results: Appropriateness score & & \\
Task performance & 7.02 & 4.40 \\
7. Answers: Correctness & & \\
\hline
\end{tabular}

\subsubsection{Constituent Skills}

As can be seen in Table 4 the entire activity lasted in average, 40.34 minutes ( $\mathrm{SD}=7.15)$, and was performed by 112.2 constituent skills $(\mathrm{SD}=35.8)$. Comparing the time spent and the frequency performing each skill, a high frequency of each skill performed can be appreciated. In other words, the participants clicked very fast to switch from one skill to another. This was particularly observed on the skills "Searching for information" and "Scanning and processing information". Previous studies found that secondary students did have more iteration between "searching" and "scanning" than adults, and this behaviour was considered as an indicator of a lack of reflection (Brand-Gruwel et al., 2009). 


\subsubsection{Sub Skills}

The average of the appropriateness score reached in the sub skills "search terms" typed in a search engine, and "selected results" from the SERP retrieved by a search engine, were 53.68 and 66.33 , respectively.

As in previous research, our participants got a low score in performing these sub skills appropriately (Walraven et al., 2008). In this line, MaKinster et al. (2002) pointed out that formulating effective searching queries is difficult for most web users. Regarding selected results from a SERP, secondary students tend to click fast on a link without much reflection (Brand-Gruwel et al., 2009), and most of them have difficulties when evaluating web information in terms of relevance and reliability (Gerjets \& Hellenthal-Schorr, 2008). In addition, it has been reported that novices are less efficient at locating useful web sites (Lazonder, 2000; MaKinster et al., 2002).

It can be concluded that the participants analysed in this study presented patterns of novice information-problem solvers, characterized by a lack of reflection when shifting skills, typing search terms, and selecting results.

\subsubsection{Task Performance}

The average of students' grade of correctness was $6.90(\mathrm{SD}=4.29)$ which means that only $43.12 \%$ of the students' answers were correct.

In Figure 3, the percentage obtained in the elaboration level is displayed. As it can be observed, most of the students did not answer the questions (53.21\%) and a high percentage (16\%) answered incorrectly. $25 \%$ of the students' answers were categorized as "elaboration on the content" and an insignificant percentage scored as "integration of the information" (Wiley, Goldman, Graesser, Sanchez, Ash, \& Hemmerich, 2009). Contrarily to previous studies (i.e., Raes et al., 2012), the participants of our study used the copy-and-paste strategy in a low proportion (3.9\%). This might be due to the specific requirements of the IPS task to be solved which demand an insightful elaboration of the answers.

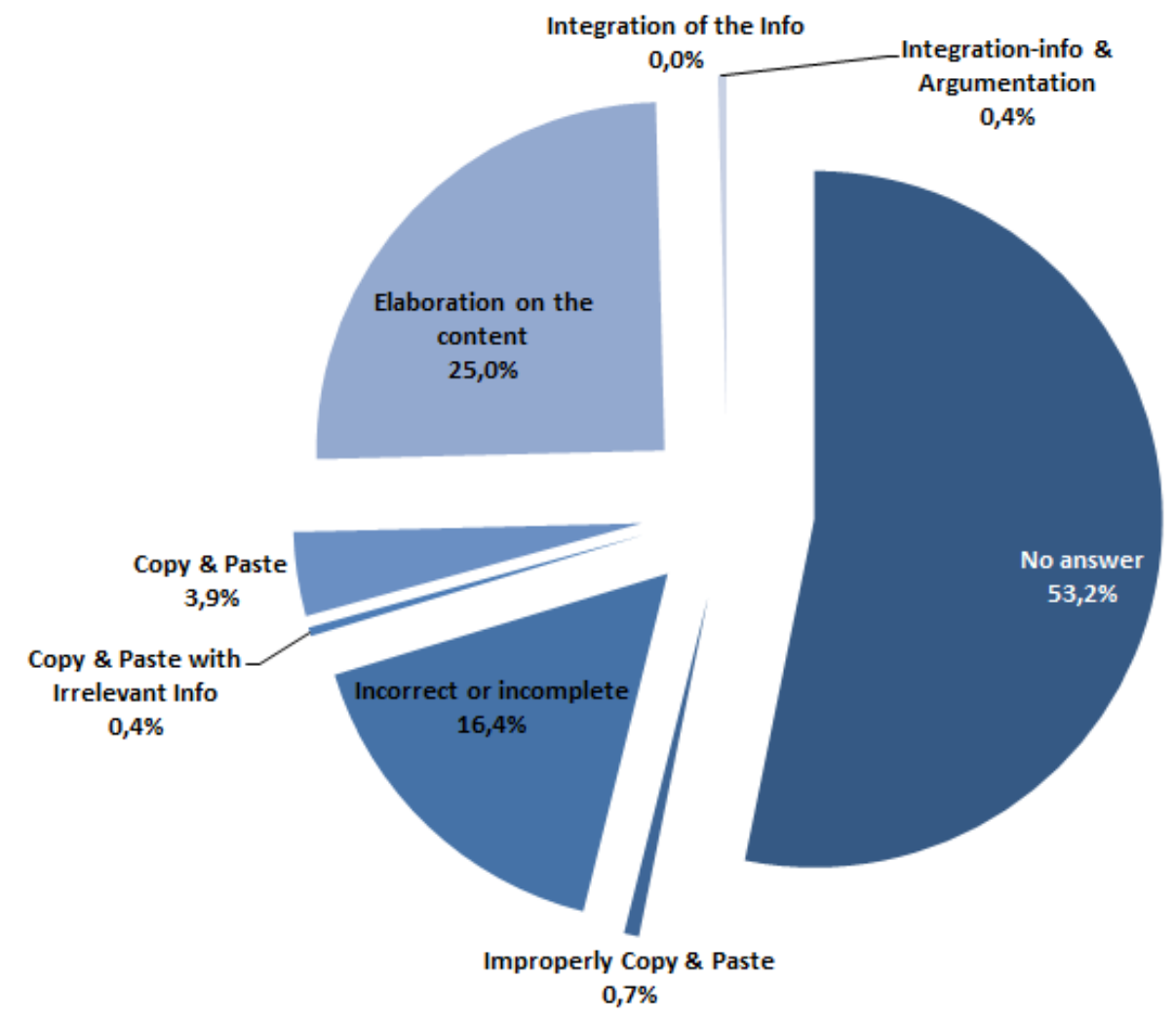

Figure 3. Task performance elaboration level

Concerning the final essay explanation level written at the end of the IPS task, twenty-seven students (67\%) did not answer. In addition, $33 \%$ of participants wrote their essay based on facts (categories 1, "separate pieces of facts", and 2, "organised facts"), and none of the students were categorized as explanation fashion (categories 3, "partial explanation" and 4, "explanation"). These results show a low rate on content understanding (Häkkarainen, 2003) (Figure 4). 


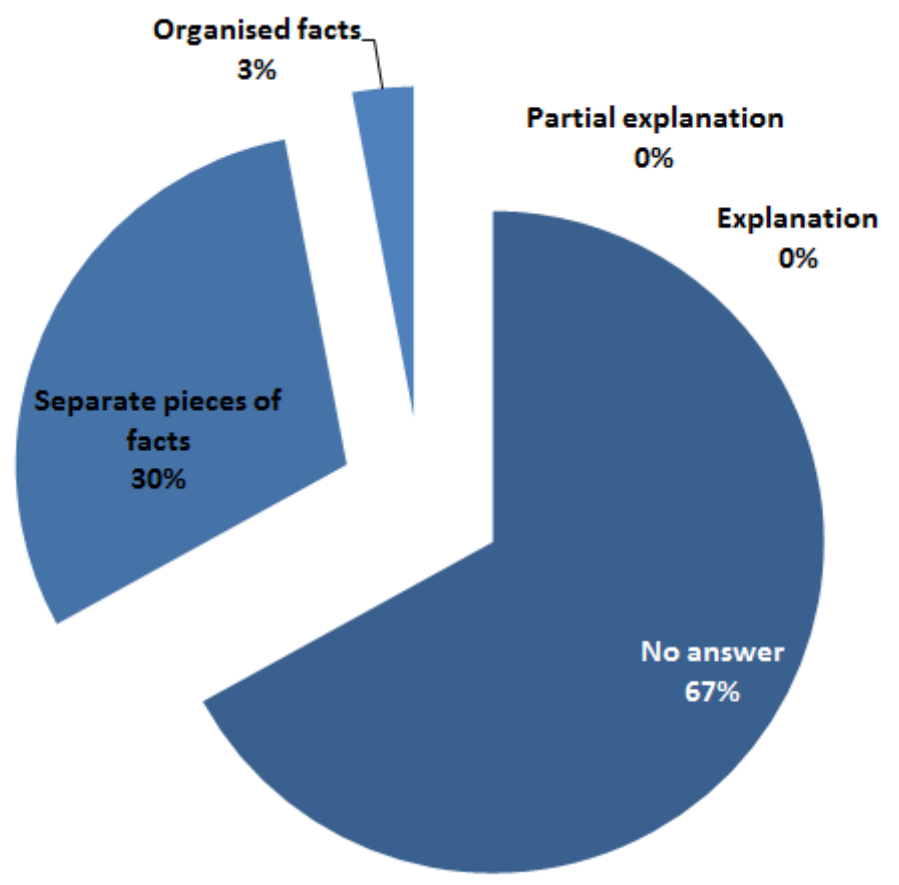

Figure 4. Final essay explanation level

As a conclusion of this section could be stated that the participants of our study went through high challenges in task performance, since they reached low scores in correctness grade, elaboration level, and explanation level.

\subsection{Gender Comparison (Research Objective 2)}

As can be seen in Table 5, no remarkable statistical differences were found in gender in relation to constituent skills, sub skills, and task performance.

Table 5. Constituent skills, sub skills, and task performance comparing girls and boys

\begin{tabular}{lrrrrr}
\hline Variables & Girls & & Boys & \\
\hline Constituent skills & M & SD & M & SD & p \\
Time spent (in minutes) & & & & & \\
1. Defining the problem & 8.13 & 3.19 & 8.92 & 2.62 & n.s. \\
2. Searching for information & 7.32 & 3.62 & 9.13 & 4.19 & n.s. \\
3. Scanning and processing information & 15.39 & 3.96 & 13.23 & 4.48 & n.s. \\
4. Organizing and presenting information & 7.89 & 5.44 & 9.38 & 5.21 & n.s. \\
Total & 39.88 & 7.97 & 42.18 & 7.10 & n.s. \\
Frequencies & & & & & \\
1. Defining the problem & 31.33 & 10.83 & 32.18 & 8.39 & n.s. \\
2. Searching for information & 20.56 & 8.68 & 24.05 & 11.84 & n.s. \\
3. Scanning and processing information & 45.17 & 14.52 & 38.36 & 17.07 & n.s. \\
4. Organizing and presenting information & 16.78 & 11.30 & 16.32 & 6.75 & .049 \\
Total & 114.56 & 35.47 & 112.05 & 37.04 & n.s. \\
Sub skills & & & & & \\
5. Search terms: Appropriateness score & 52.15 & 24.19 & 54.94 & 19.75 & n.s. \\
6. Selected results: Appropriateness score & 67.59 & 21.83 & 65.30 & 20.91 & n.s. \\
Task performance & & & & & \\
7. Answers: Correctness & 7.22 & 4.44 & 6.86 & 4.46 & n.s. \\
\hline
\end{tabular}

However, if we consider the elaboration level of the answers given by students, we can found some statistical differences (Figure 5) in the use of the "Copy \& Paste" strategy. Although the average was low, girls copied and pasted the information more frequently than boys (girls: $\mathrm{M}=.39, \mathrm{SD}=.61$; boys: $\mathrm{M}=.18, \mathrm{SD}=.39 ; \mathrm{p}=.014$ ). In addition, girls answered some questions copying and pasting irrelevant information (girls: $\mathrm{M}=.06, \mathrm{SD}=.24$; boys: $\mathrm{M}=.00, \mathrm{SD}=.00$; $\mathrm{p}=.024$ ) and some questions copying and pasting information in an improper way (girls: $\mathrm{M}=.11, \mathrm{SD}=.32$; boys: $\mathrm{M}=.00$, $\mathrm{SD}=.00 ; \mathrm{p}=.001$ ). Contrarily to the findings of previous research (i.e., Chang, Chen, Huang, \& Chou, 2015), in our study girls used the "Copy \& Paste" strategies more than boys. 


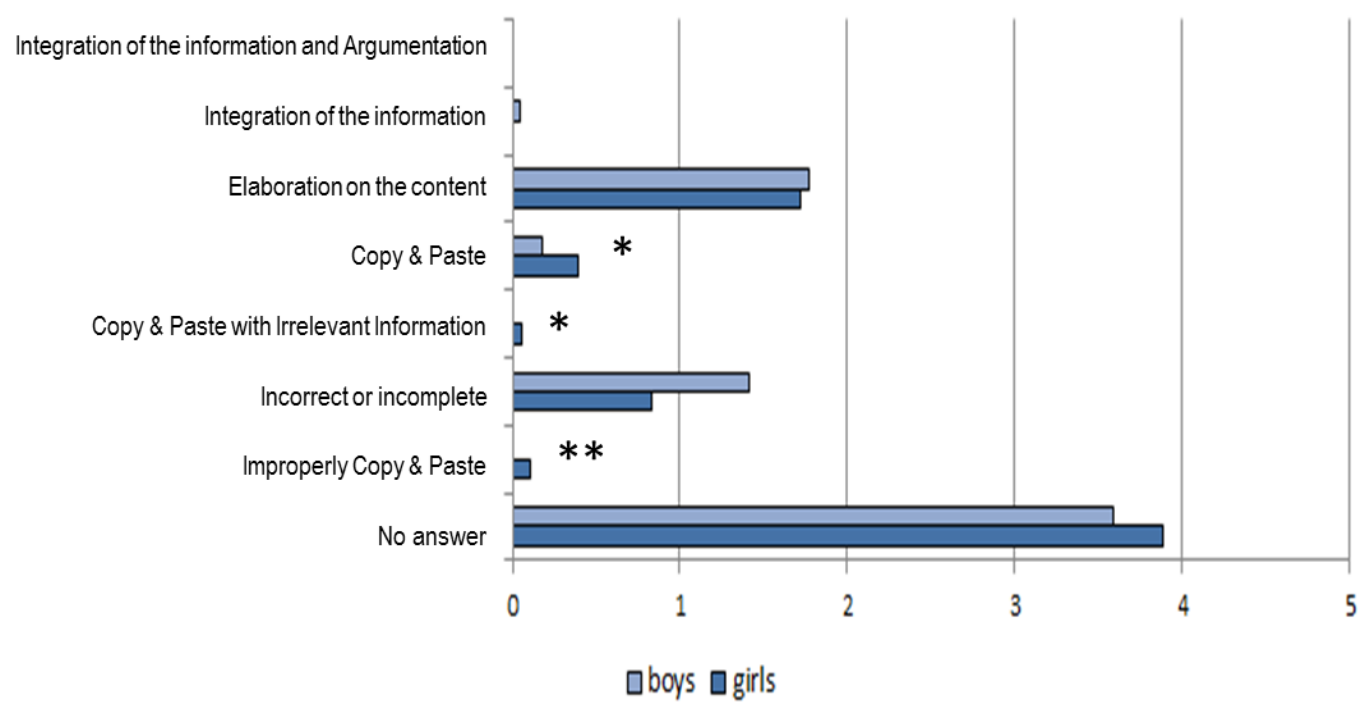

Figure 5. Elaboration level on the information-gathering answers $\left({ }^{*} \mathrm{p}<.05 ; * * \mathrm{p}<.01\right)$

In reference to the level of explanation of the final essay, any significant statistical differences were found between both groups, according the gender variable (girls: $\mathrm{M}=.33, \mathrm{SD}=.485$; boys: $\mathrm{M}=.32, \mathrm{SD}=.568 ; \mathrm{p}=\mathrm{n} . \mathrm{s}$.).

\section{Conclusions and Educational Implications}

Our results revealed that secondary students face several challenges in the development of an efficient IPS process and task performance. In regard to variable gender, no important differences were found in our analyses. Both girls and boys have similar difficulties in solving information problems. Consequently, it is required to help students to develop better IPS skills and sub skills, and task performance. From our perspective, we consider that it is necessary to be aware of the difficulties that students usually face in IPS tasks in their classrooms, in order to support students to overcome such challenges.

Considering the contributions made by our study regarding the secondary students' challenges on IPS and the theoretical and methodological contributions of other studies, we propose that the design of an instructional process should be based on the following three instructional principles: (1) embedding the IPS skills in the scholar curriculum to learn the current subjects through meaningful and authentic contents, (2) structuring the students' problem solving, and (3) supporting the students' problem resolution by a series of scaffolds to guide the students' progress.

Related to the first instructional principle, IPS skills should be acquired and embedded within a relevant and meaningful learning content. Some effective embedded instruction research studies have showed a positive impact on learning IPS skills (Britt \& Aglinskas, 2002; Raes et al., 2012), on enhancing students' performance on domain contents (Raes et al., 2012), and on transferring IPS skills to other contexts (Walraven, Brand-Gruwel, \& Boshuizen, 2010).

As regards to the second instructional principle, structuring the instruction, it is worth highlighting the importance of guiding students through the whole process of information problem resolution. Scaffolding helps to accomplish all the steps needed to successfully solve a problem through providing a layer of structure between student and Internet (Segers \& Verhoeven, 2009). A good structured instruction on IPS could be an instruction that follows the Inquiry-Web Learning methodology as proposed in WebQuest (Dodge, 1995).

Related to the third instructional principle, supporting the instruction, we claim the necessity to design lessons which could provide scaffolds in each IPS skill and sub skill in order to tackle information problems. Sociocultural theory introduced the notion of scaffolding (Vygotsky, 1978; Wood, Bruner, \& Ross, 1976) tailored to the needs of students with the intention of helping them to progress on their learning process. Educational research has already provided successful evidence about the improvement of IPS skills and individual learning in a technology environment by implementing appropriate questions and reflection prompts that trigger students to activate key cognitive processes to solve the learning task (Raes et al., 2012; Walhout et al., 2015). Scaffolds could be embedded in the IPS task to give guidance and support to learn IPS skills and sub skills, and gradually withdraw them as the instructional process progresses.

Following previous studies (Badia \& Becerril, 2015; De Vries, Van der Meij \& Lazonder, 2008; Morris et al., 2010; Pifarré, 2009; Pifarré, Cobos, \& Argelagós, 2014; Stadtler \& Bromme, 2008; Walraven et al., 2010, Wopereis, Brand-Gruwel, \& Vermetten, 2008), the instructional process might be scaffolded by means of questions, worksheets, scripts, and prompts (Stadler \& Brome, 2008). For instance, scaffolds could be designed as it follows: (a) driving questions in order to encourage the activation of students' prior knowledge; (b) prompts to perform a specific IPS skill, i.e., 
"write down the specific information you will need to solve this problem" (skill "defining the Problem"); (c) pop-up messages to guide a search; (d) worksheets to promote reflection about search terms or selection of the results (skill "searching for information"), and (e) maps to organize the information and writing templates (skill "organizing and presenting information").

The present study is an attempt to give an insight into the challenges of secondary students in the field of IPS and to draw educational guidelines for the design of IPS instruction in school. Nonetheless, our findings must be carefully interpreted due to the following two limitations. First, the technique used to collect the data was the log files technique, which may bring the risk to over interpret the actions made by the participants (Argelagós, Jarodzka, \& Pifarré, 2011). As this technique only captures the actions made on the screen, some actions can easily be misinterpreted. The election of this technique was due to the ecological validity and the unobtrusiveness of the technique (Wopereis \& van Merriënboer, 2011); however, the cognitive processes involved in IPS could be more in-depth analysed through other techniques as eye-tracking (Holmqvist, Nyström, Andersson, Dewhurst, Jarodzka, \& van de Weijer, 2011) or cued-retrospective reports (van Gog, Paas, van Merriënboer, \& Witte, 2005) though they can only be applied in laboratory settings. Second, the sample considered for this study -40 students - might be a slightly limited segment.

Notwithstanding the above limitations, this paper examined the challenges that secondary students face when solving a problem using digital information to learn curricular contents. Our findings draw inferences to help secondary students to enhance their IPS skills in everyday classrooms. We claim that this study might contribute to coaching secondary students into digital competences that may allow them an adequate use of web information.

\section{Acknowledgments}

This research was funded by the Ministerio de Ciencia y Tecnología of the Spanish Government (Project Number: EDU2009-11656). The authors would like to thank the teachers and the pupils for their participation in the study reported in this paper.

\section{References}

Arcand, M., Nantel, J., \& Sénécal, S. (2011). The effects of sex and Internet usage on search efficiency and effectiveness. International Journal of Computer Information Systems and Industrial Management Applications, 3, 663-670.

Argelagós, E., \& Pifarré, M. (2012). Improving information problem solving skills in secondary education through embedded instruction. Computers in Human Behavior, 28(2), 515-526. http://dx.doi.org/10.1016/j.chb.2011.10.024

Argelagós, E., Jarodzka, H., \& Pifarré, M. (2011, August). Measuring cognitive processes involved in web search: log files, eye-movements and cued retrospective reports compared. Paper presented at the 12nd Biennial Conference EARLI (European Association for Research on Learning and Instruction), Exeter, United Kingdom.

Azevedo, R., Cromley, J. G., \& Seibert, D. (2004). Does adaptive scaffolding facilitate students' ability to regulate their learning with hypermedia? Contemporary Educational Psychology, 29(3), 344-370. http://dx.doi.org/10.1016/j.cedpsych.2003.09.002

Badia, A., \& Becerril, L. (2015). Collaborative solving of information problems and group learning outcomes in secondary education. Journal for the Study of Education and Development, 38(1), 67-101. http://dx.doi.org/10.1080/02103702.2014.996403.

Badilla-Quintana, M. G., Cortada-Pujol, M., \& Riera-Romaní, J. (2011). Internet navigation and information search strategies: how do children are influenced by their participation in an intensive ICT project. International Journal of Technology and Design Education. http://dx.doi.org/10.1007/s10798-011-9158-4

Bannert, M., \& Reimann, P. (2011). Supporting self-regulated hypermedia learning through prompts. Instructional Science, 40(1), 193-211. http://dx.doi.org/10.1007/s11251-011-9167-4.

Brand-Gruwel, S., \& Stadtler, M. (2011). Solving information-based problems: Evaluating sources and information. Learning and Instruction, 21(2), 175-179. http://dx.doi.org/10.1016/j.learninstruc.2010.02.008

Brand-Gruwel, S., Wopereis, I., \& Vermetten, Y. (2005). Information-problem solving by experts and novices: analysis of a complex cognitive skill. Computers in Human Behavior, 21, 487-508. http://dx.doi.org/10.1016/j.chb.2004.10.005

Brand-Gruwel, S., Wopereis, I., \& Walraven, A. (2009). A descriptive model of information-problem solving while using internet. Computers \& Education, 53, 1207-1217. http://dx.doi.org/10.1016/j.compedu.2009.06.004

Britt, M. A., \& Aglinskas, C. (2002). Improving students' ability to identify and use source information. Cognition and Instruction, 20(4), 485-522. http://dx.doi.org/10.1207/S1532690XCI2004_2

Chang, C. M., Chen, Y. L., Huang, Y. Y., \& Chou, C. (2015). Why do they become potential cyber-plagiarizers? Exploring 
the alternative thinking of copy-and-paste youth in Taiwan. Computers \& Education, 87, 357-367. http://dx.doi.org/10.1016/j.compedu.2015.07.006

Chen, S. Y., \& Fu, Y. C. (2009). Internet use and academic achievement: Gender differences in early adolescence. Adolescence, 44(176), 797-821.

Chen, S. Y., \& Macredie, R. (2010). Web-based interaction: a review of three important human factors. International Journal of Information Management, 30(5), 379-387. http://dx.doi.org/10.1016/j.ijinfomgt.2010.02.009

De Vries, B., van der Meij, H., \& Lazonder, A.W. (2008). Supporting reflective web searching in elementary schools. Computers in Human Behavior, 24, 649-665. http://dx.doi.org/10.1016/j.chb.2007.01.021

Dodge, B. (1995). WebQuests: A technique for internet-based learning. Distance Educator, 1(2), 10-13.

Eisenberg, M. B., \& Berkowitz, R. E. (1990). Information-problem-solving: The big six skills approach to library and information skills instruction. Norwood, NJ: Ablex.

Fidel, R., Davies, R. K., Douglass, M. H., Holder, J. K., Hopkins, C. J., Kushner, E. J., et al. (1999). A visit to the information mall: Web searching behavior of high school students. Journal of the American Society of Information Science, 50(1), 24-37.

Gerjets, P., \& Hellenthal-Schorr, T. (2008). Competent information search in the World Wide Web: development and evaluation of a web training for pupils. Computers in Human Behavior, 24, 693-715. http://dx.doi.org/10.1016/j.chb.2007.01.029

Gerjets, P., Kammerer, Y., \& Werner, B. (2011). Measuring spontaneous and instructed evaluation processes during Web search: Integrating concurrent thinking-aloud protocols and eye-tracking data. Learning and Instruction, 21, 220-231. http://dx.doi.org/10.1016/j.learninstruc.2010.02.005

Goldman, S. R. (2011). Commentary: Choosing and using multiple information sources: Some new findings and emergent issues. Learning and Instruction, 21(2), 238-242. http://dx.doi.org/10.1016/j.learninstruc.2010.02.006

Häkkarainen, K. (2003). Emergence of progressive-inquiry culture in computer-supported collaborative learning. Learning Environments Research, 6, 199-220. https://doi.org/10.1023/A:1024995120180

Hargittai, E., \& Shafer, S. (2006). Differences in actual and perceived online skills: the role of gender. Social Science Quarterly, 87(2), 432-448. https://doi.org/10.1111/j.1540-6237.2006.00389.x

Holmqvist, K., Nyström, N., Andersson, R., Dewhurst, R., Jarodzka, H., \& van de Weijer, J. (2011). Eye tracking: a comprehensive guide to methods and measures. Oxford, UK: Oxford University Press.

Jackson, L. A., Von Eye, A., Witt, E. A., Zhao, Y., \& Fitzgerald, H. E. (2011). A longitudinal study of the effects of Internet use and videogame playing on academic performance and the roles of gender, race and income in these relationships. Computers in Human Behavior, 27(1), 228-239. http://dx.doi.org/10.1016/j.chb.2010.08.001

Jonassen, D. H., \& Kim, B. (2009). Arguing to learn and learning to argue: Design justifications and guidelines. Educational Technology: Research \& Development, 58, 439-457. http://dx.doi.org/10.1007/s11423-009-9143-8

Karavidas, M., Lim, N. K., \& Katsikas, S. L. (2005). The effects of computers on older adult users. Computers in Human Behavior, 21(5), 697-711. http://dx.doi.org/10.1016/j.chb.2004.03.012

Ladbrook, J., \& Probert, E. (2011). Information skills and critical literacy: Where are our digikids at with online searching and are their teachers helping? Australasian Journal of Educational Technology, 27(1), 105-121. https://doi.org/10.14742/ajet.986

Large, A., Beheshti, J., \& Rahman, T. (2002). Gender differences in collaborative web searching behavior: an elementary school study. Information Processing \& Management, 38(3), 427-443. http://dx.doi.org/10.1016/S0306-4573(01)00034-6

Lazonder, A. W. (2000). Exploring novice users' training needs in searching information on the WWW. Journal of Computer Assisted Learning, 16, 326-335. http://dx.doi.org/1010.1046/j.1365-2729.2000.00145.x

Lorenzen, M. (2002). The land of confusion? High school students and their use of the world wide web for research. Research Strategies, 18(2), 151-163. http://dx.doi.org/10.1016/S0734-3310(02)00074-5

Lorigo, L., Pan, B., Hembrooke, H., Joachims, T., Granka, L., \& Gay, G. (2006). The influence of task and gender on search and evaluation behavior using Google. Information Processing \& Management, 42(4), 1123-1131. http://dx.doi.org/10.1016/j.ipm.2005.10.001

Makinster, J. G., Beghetto, R. A., \& Plucker, J. A. (2002). Why can’t I find Newton's third law? Case studies of students' 
use of the web as a science resource. Journal of Science Education and Technology, 11, 155-172. http://dx.doi.org/10.1023/A:1014617530297

Mason, L., Ariasi, N., \& Boldrin, A. (2011). Epistemic beliefs in action: spontaneous reflections about knowledge and knowing during online information searching and their influence on learning. Learning and Instruction, 21(1), 137-151. http://dx.doi.org/10.1016/j.learninstruc.2010.01.001.

Morris, R., Hadwin, A. F., Gress, C. L. Z., Miller, M., Fior, M., Church, H., \& Winne, P. H. (2010). Designing roles, scripts, and prompts to support CSCL in gStudy. Computers in Human Behavior, 26(5), 815-824. http://dx.doi.org/10.1016/j.chb.2008.12.001

Nickerson, R.S. (1995). Can technology help teach for understanding? In D. N. Perkins, J. L. Schwartz, M. M. West, \& M. S. Wiske (Eds.), Software goes to school: Teaching for understanding with new technologies (pp. 7-22). New York: Oxford University Press.

Papastergiou, M., \& Solomonidou, C. (2005). Gender issues in Internet access and favourite Internet activities among Greek high school pupils inside and outside school. Computers \& Education, 44(4), 377-393. http://dx.doi.org/10.1016/j.compedu.2004.04.002

Pifarré, M. (2009). Inquiry Web-based learning to enhance knowledge construction in Science: A study in Secondary Education. In B. A. Morris, \& G. M. Ferguson (Eds.), Computer-Assisted Teaching: New Developments. New York: Nova Science Publishers, Inc. Retrieved from http://hdl.handle.net/10459.1/56629

Pifarré, M., Cobos, R., \& Argelagós, E. (2014). Incidence of group awareness information on students' collaborative learning processes. Journal of Computer Assisted Learning, 30(4), 300-317. http://dx.doi.org/10.1111/jcal.12043

Priemer, B., \& Ploog, M. (2007). The influence of text production on learning with the Internet. British Journal of Educational Technology, 38(4), 613-622. http://dx.doi.org/10.1111/j.1467-8535.2006.00646.x

Probert, E. (2009). Information literacy skills: Teacher understandings and practice. Computers \& Education, 53, 24-33. http://dx.doi.org/10.1016/j.compedu.2008.12.018

Raes, A., Schellens, T., De Wever, B., \& Vanderhoven, E. (2012). Scaffolding information problem solving in web-based collaborative inquiry learning. Computers \& Education, $59(1), \quad 82-94$. http://dx.doi.org/10.1016/j.compedu.2011.11.010

Rouet, J. F., Ros, C., Goumi, A., Macedo-Rouet, M., \& Dinet, J. (2011). The influence of surface and deep cues on primary and secondary school students' assessment of relevance in Web menus. Learning and Instruction, 21(2), 205-219. http://dx.doi.org/10.1016/j.learninstruc.2010.02.007

Roy, M., \& Chi, M. T. (2003). Gender differences in patterns of searching the web. Journal of educational computing research, 29(3), 335-348. http://dx.doi.org/10.2190/7BR8-VXA0-07A7-8AVN

Scardamalia, M., \& Bereiter, C. (1991). Higher levels of agency for children in knowledge-building: A challenge for the design of new knowledge media. The Journal of the Learning Sciences, 1(1), 37-68. http://dx.doi.org/10.1207/s15327809jls0101_3

Segers, E., \& Verhoeven, L. (2009). Learning in a sheltered environment: the use of webquest. Learning and Instruction, 19, 423-432. http://dx.doi.org/10.1016/j.learninstruc.2009.02.017

Stadtler, M., \& Bromme, R. (2008). Effects of the metacognitive tool met.a.ware on the web search of laypersons. Computers in Human Behavior, 24, 716-737. http://dx.doi.org/10.1016/j.chb.2007.01.023

Tsai, M. J. (2009). Online Information Searching Strategy Inventory (OISSI): A quick version and a complete version. Computers \& Education, 53(2), 473-483. http://dx.doi.org/10.1016/j.compedu.2009.03.006

Tsai, M. J., \& Tsai, C. C. (2010). Junior high school students' Internet usage and self-efficacy: A re-examination of the gender gap. Computers \& Education, 54(4), 1182-1192. http://dx.doi.org/10.1016/j.compedu.2009.11.004

Van Deursen, A. J. A. M., \& Van Diepen, S. (2013). Information and strategic Internet skills of secondary students: A performance test. Computers \& Education, 63, 218-226. http://dx.doi.org/10.1016/j.compedu.2012.12.007

Van Deursen, A. J., Görzig, A., van Delzen, M., Perik, H. T., \& Stegeman, A. G. (2014). Primary school children's internet skills: A report on performance tests of operational, formal, information, and strategic internet skills. International Journal of Communication, 8, 1343-1365.

Van Gog, T., Paas, F., van Merriënboer, J. J. G., \& Witte, P. (2005). Uncovering the problem-solving process: Cued retrospective reporting versus concurrent and retrospective reporting. Journal of Experimental Psychology: Applied, 11, 237-244. http://dx.doi.org/10.1037/1076-898X.11.4.237 
Vygotsky, L. (1978). Interaction between learning and development. Readings on the development of children, 23(3), 34-41.

Walhout, J., Brand-Gruwel, S., Jarodzka, H., van Dijk, M., de Groot, R., \& Kirschner, P. A. (2015). Learning and navigating in hypertext: Navigational support by hierarchical menu or tag cloud? Computers in Human Behavior, 46, 218-227. http://dx.doi.org/10.1016/j.chb.2015.01.025

Wallace, R., Kupperman, J., Krajcik, J., \& Soloway, E. (2000). Science on the Web: Students Online in a Sixth-Grade Classroom. Journal of the Learning Sciences, 9(1), 75-104. http://dx.doi.org/10.1207/s15327809jls0901_5

Walraven, A., Brand-Gruwel, S., \& Boshuizen, H. P. A. (2008). Information-problem solving: A review of problems students encounter and instructional solutions. Computers in Human Behavior, 24, 623-648. http://dx.doi.org/10.1016/j.chb.2007.01.030

Walraven, A., Brand-Gruwel, S., \& Boshuizen, H. P. A. (2010). Fostering transfer of web searchers' evaluation skills: A field test of two transfer theories. Computers in Human Behavior, 26, 716-728. http://dx.doi.org/10.1016/j.chb.2010.01.008

Wiley, J., \& Voss, J. F. (1999). Constructing arguments from multiple sources: Tasks that promote understanding not just memory for text. Journal of Educational Psychology, 91, 301-311. http://dx.doi.org/10.1037/0022-0663.91.2.301

Wiley, J., Goldman, S. R., Graesser, A. C., Sanchez, C. A., Ash, I. K., \& Hemmerich, J. A. (2009). Source evaluation, comprehension, and learning in Internet science inquiry tasks. American Educational Research Journal, 46, 1060-1106. http://dx.doi.org/10.3102/0002831209333183

Wood, D. (2009). Comments on "Learning with ICT: New perspectives on help seeking and information searching". Computers \& Education, 53, 1048-1051. http://dx.doi.org/10.1016/j.compedu.2009.07.002

Wood, D., Bruner, J., \& Ross, G. (1978). The role of tutoring in problem solving. Journal of Child Psychology and Psychiatry, 17, 89-100. http://dx.doi.org/10.1111/j.1469-7610.1976.tb00381.x

Wopereis, I. G. J. H., \& Van Merriënboer, J. J. G. (2011). Evaluating text-based information on the World Wide Web. Learning and Instruction, 21, 232-237. http://dx.doi.org/10.1016/j.learninstruc.2010.02.003

Wopereis, I., Brand-Gruwel. S., \& Vermetten, Y. (2008). The effect of embedded instruction on solving information problems. Computers in Human Behavior, 24, 738-752. http://dx.doi.org/10.1016/j.chb.2007.01.024

Young, B. J. (2000). Gender differences in student attitudes toward computers. Journal of research on computing in education, 33(2), 204-216. http://dx.doi.org/10.1080/08886504.2000.10782310

Zhou, M. (2014). Gender difference in web search perceptions and behavior: Does it vary by task performance? Computers \& Education, 78, 174-184. http://dx.doi.org/10.1016/j.compedu.2014.06.005.

\section{Copyrights}

Copyright for this article is retained by the author(s), with first publication rights granted to the journal.

This is an open-access article distributed under the terms and conditions of the Creative Commons Attribution license which permits unrestricted use, distribution, and reproduction in any medium, provided the original work is properly cited. 